\title{
O LUGAR DA CULTURA NO DEBATE SOBRE SEGURANÇA ALIMENTAR E NUTRICIONAL: UM OLHAR A PARTIR DE MOÇAMBIQUE
}

\author{
THE PLACE OF CULTURE ON THE \\ FOOD AND NUTRITIONAL SECURITY \\ DEBATE: A VIEW FROM MOZAMBIQUE
}

\section{Renata Menasche}

renata.menasche@gmail.com

Doutora em Antropologia Social. Professora do Programa de Pós-Graduação em Antropologia da

Universidade Federal de Pelotas (PPGAnt/UFPel) e do Programa de Pós-Graduação em Desenvolvimento Rural da Universidade Federal do Rio Grande do Sul (PGDR/UFRGS). Coordenadora do Grupo de Estudos e Pesquisas em Alimentação, Consumo e Cultura (GEPAC - https://www.ufrgs.br/gepac/)

Orcid: https://orcid.org/0000-0002-8707-6037

\section{Jone Januário Mirasse}

jmirasse@gmail.com

Engenheiro agrônomo, Mestre em Desenvolvimento Rural. Pesquisador pela Direcção Nacional de Gestão e Garantia da Qualidade no Ministério da Educação e Desenvolvimento Humano, Maputo, Moçambique.

Orcid: https://orcid.org/0000-0002-0130-9822

\section{Fabiana Thomé da Cruz}

fabianathome@ufg.br

Engenheira de Alimentos, doutora em Desenvolvimento Rural. Professora da Escola de Agronomia/ Universidade Federal de Goiás (EA/UFG).

Orcid: https://orcid.org/0000-0001-8697-7362

\section{RESUMO}

Este artigo problematiza o lugar da cultura alimentar em projetos e políticas públicas voltados à segurança alimentar e nutricional (SAN). São analisados dados empíricos de pesquisa acerca de um programa público na província de Nampula (Nordeste de Moçambique) por meio do qual famílias rurais foram estimuladas a produzir e consumir batata-doce de polpa alaranjada. Apesar de nutritivo, esse tubérculo — por razões que remetem ao sofrimento vivenciado no processo de colonização e ao respeito aos ancestrais - é aceito com restrições pela população. Desse modo, seu emprego para combater a insegurança alimentar pode ser considerado pouco eficaz. Esse contexto, favorável à análise das interfaces entre cultura alimentar e SAN, proporciona refletir sobre como se conformam, em uma sociedade, adesões, adaptações ou rejeições a práticas alimentares nela introduzidas.

Palavras-chave: Segurança alimentar e nutricional. Cultura alimentar. Políticas públicas.

\begin{abstract}
This paper aims to discuss the place of food culture in the conception and execution of projects and public policies concerning food and nutritional security (SAN, from its initials in Portuguese). The study analyses empirical data from a research about a public program in Nampula province, northeast of Mozambique. Through this program, rural
\end{abstract}


families were encouraged to produce and consume sweet potato of orange flesh. In spite of its nourishing property, this tuber is accepted with restrictions by the local population since it is related to the suffering of the colonial time and to the respect towards their ancestors. Consequently, the use of this vegetable to fight food insecurity might be ineffective. This context, which is favorable to analyse the interface between food culture and SAN, provides thinking about how adhesion, adaptation and rejection to new food practices take place.

Keywords: Food and nutritional security. Food culture. Public policies.

Nos anos recentes, o tema Segurança Alimentar e Nutricional (SAN) tem se colocado, nacional e internacionalmente, no centro das agendas de pesquisa e de políticas públicas. No Brasil, a trajetória dos debates em torno do tema confluiu na definição de SAN, reconhecida por meio de Lei Orgânica ${ }^{1}$, que entende que

A segurança alimentar e nutricional consiste na realização do direito de todos ao acesso regular e permanente a alimentos de qualidade, em quantidade suficiente, sem comprometer o acesso a outras necessidades essenciais, tendo como base práticas alimentares promotoras de saúde que respeitem a diversidade cultural e que sejam ambiental, cultural, econômica e socialmente sustentáveis (BRASIL, 2006).

A reflexão a que aqui nos propomos toma essa definição como ponto de partida para problematizar o lugar da cultura alimentar na concepção e execução de iniciativas, projetos e políticas voltados à segurança alimentar e nutricional.

Para tanto, optamos por trazer à discussão dados empíricos originários de uma pesquisa realizada no continente africano, em Moçambique, referente a percepções de famílias rurais receptoras de um programa público em $\mathrm{SAN}^{2}$. Tal pesquisa teve origem nas inquietações de um jovem profissional moçambicano cuja inserção em órgão de execução de tal política pública levara à reflexão sobre seus percalços. Os dados sistematizados e analisados neste artigo foram, assim, gerados a campo por um dos autores — a etnografia foi realizada durante um período de cerca de três meses, em viagem de retorno a Moçambique ocorrida entre o cumprimento dos créditos em disciplinas e a escrita do trabalho - e, posteriormente, para além das análises presentes em sua dissertação, foram retomados e analisados para a elaboração do presente artigo. A escolha da província de Nampula, situada no Nordeste moçambicano, para realização da pesquisa está associada à significância de sua produção agrícola e ao fato de ter sido uma das primeiras províncias do Norte do país a receber o programa de produção, multiplicação e distribuição, entre famílias rurais, de ramas de batata-doce de polpa alaranjada.

Apesar de muito nutritiva, essa batata é alimento aceito com fortes restrições pela população estudada. Partindo dessa constatação, a pesquisa realizada por Mirasse (2010) interrogou sobre as causas dessa rejeição, buscando respostas junto àqueles que não são comumente escutados quando do planejamento ou da avaliação de políticas públicas. Os dados foram obtidos por meio de entrevistas semiestruturadas e observação participante realizadas junto a líderes comunitários, técnicos e gestores, mas especialmente junto a famílias rurais. A abordagem adotada procurou, assim, privilegiar o modo como as comunidades rurais estudadas experienciam a produção e o consumo de alimentos, no que guarda identidade com estudos como o de Maria do Carmo Soares de Freitas (2003), conduzido em bairro popular da cidade baiana de Salvador, onde a autora realiza uma etnografia da fome. Nesse importante trabalho, tendo presente que a fome é "fenômeno produzido pelo contexto político, 
social, histórico e econômico", a autora conduz o olhar de modo a evidenciar que esses "elementos do tecido macrossocial estão inseridos no mundo íntimo e cotidiano, conforme a interpretação dos famintos" (FREITAS, 2002, p. 56). Desse modo, ela busca desvelar o fenômeno estudado - no caso, a fome - a partir do ponto de vista de quem o vive.

Antes de explorar os dados empíricos do caso escolhido, cabe, para iluminar a reflexão aqui proposta, uma breve introdução sobre as relações entre alimentação e cultura, particularmente em contexto de globalização. Além desta introdução e do item que a segue, que propõe, então, pensar a comida como expressão da cultura, o trabalho está organizado em mais dois outros tópicos. O terceiro tópico proporciona apreender o contexto no qual foi implementado o programa para difusão de batata-doce de polpa alaranjada em Moçambique para, na sequência, discutir, por meio da relação de dominação em que esse alimento foi introduzido, as restrições quanto a sua produção e consumo. No item seguinte, em que são tecidas as considerações finais do artigo, a partir das evidências empíricas apresentadas em relação ao caso moçambicano estudado, é retomada a discussão sobre o lugar da cultura para a efetividade de ações voltadas à segurança alimentar e nutricional.

\section{COMIDA COMO EXPRESSÃO DA CULTURA}

Sabemos que o processo de globalização impõe movimento de padronização e uniformização dos produtos, gostos e comportamentos alimentares. Mas cabe notar que, ao mesmo tempo, há resistências e afirmação do local. De outro modo, como entender, como mostra Rial (1996, p. 6), que as cadeias de fast-food ofereçam, nos diferentes países, sugestões de combinações de itens que tendem a se aproximar das refeições locais usualmente servidas?

Podemos considerar que, concomitantemente ao processo de globalização, que promove intensa padronização, ocorra diversificação em escala local. É o que indica Canclini (1997, p. 19), ao analisar tendências contemporâneas no consumo e na cidadania: não se pode entender o global como substituto do local. Assim, a relação da globalização com as culturas locais e regionais não é apenas de homogeneização: as diferenças podem persistir, sendo, muitas vezes, apropriadas pelo mercado - o que permite entender, por exemplo, a presença de água de coco e de caldo verde respectivamente nos cardápios brasileiro e português da rede de fast-food comumente lembrada como ícone da globalização da alimentação.

Afinal, como afirma Rocha (1985, p. 67), é na esfera do consumo que os objetos - e aí podemos incluir os alimentos - adquirem sentido, produzindo significações e distinções sociais, levando aos consumidores os "universos simbólicos que a eles foram atribuídos". Dessa forma, a homogeneização dos modelos de consumo - no caso, alimentar — deve ser relativizada, uma vez que

(...) os elementos que têm em comum são, de fato, interpretados segundo a cultura de cada povo e país, inserindo-se em estruturas ainda fortemente marcadas pelas particularidades locais que, por sua vez, foram-se formando na sequência de um processo histórico longo e articulado (FLANDRIN; MONTANARI, 1998, p. 867)

Essa compreensão é também sugerida por Garrigues-Cresswell e Martin (1998, p. 13-15), para quem os comportamentos alimentares revelam, mais que um jogo sutil entre a resistência e a mudança ou entre a tradição e a modernidade, "as estratégias que permitem a um grupo e aos indivíduos que o 
constituem demarcar simultaneamente uma identidade e uma distinção local”. Afinal, como ensina Mintz (2001, p. 31-32):

\begin{abstract}
Nossas atitudes em relação à comida são normalmente aprendidas cedo e bem e são, em geral, inculcadas por adultos afetivamente poderosos, o que confere ao nosso comportamento um poder sentimental duradouro. Devemos comer todos os dias, durante toda nossa vida; crescemos em lugares específicos, cercados também de pessoas com hábitos e crenças particulares. Portanto, o que aprendemos sobre comida está inserido em um corpo substantivo de materiais culturais historicamente derivados. A comida e o comer assumem, assim, uma posição central no aprendizado social por sua natureza vital e essencial, embora rotineira. $\mathrm{O}$ comportamento relativo à comida revela repetidamente a cultura em que cada um está inserido. (...) Os hábitos alimentares podem mudar inteiramente quando crescemos, mas a memória e o peso do primeiro aprendizado alimentar e algumas das formas sociais aprendidas através dele permanecem, talvez para sempre, em nossa consciência (MINTZ, 2001, p. 31-32).
\end{abstract}

Dado que as experiências alimentares vividas ficam, assim, aderidas à memória, tomando parte na conformação do que somos, é que podemos apreender a comida como constitutiva de identidades e relações sociais, de modo a consideraras múltiplas formas de sua expressão como indicadoras da diversidade cultural existente.

É nesse quadro que podemos apreender a diferença, proposta pelo antropólogo DaMatta (1987, p. 22), entre alimento e comida, apontados como par semântico de grande importância na gramática culinária brasileira:

\begin{abstract}
pode-se argumentar que na lógica do 'comer' e da 'comensalidade' brasileiras há um notável esforço de conjugação dos aspectos universais da alimentação (o seu valor nutritivo, a sua capacidade de gerar energia e sustentar o corpo, o seu teor proteico etc.) com suas definições simbólicas, posto que 'nem só de pão vive o homem' e o ato de comer tem uma enorme importância social. (...) Qualquer brasileiro sabe que toda substância nutritiva é 'alimento', mas sabe também que nem todo alimento é 'comida'. De fato, para transformar um alimento em comida, é preciso não só o ato crítico do cozimento, mas também o modo pelo qual o alimento é preparado (DAMATTA, 1987, p. 22).
\end{abstract}

A comida é, então, entendida como alimento transformado pela cultura. E é tomando a comida como expressão da cultura ${ }^{3}$ que podemos entender que, em um contexto de globalização, em que da industrialização da alimentação em escala planetária decorre uma intensa padronização de produtos, gostos e comportamentos alimentares, observamos, ao mesmo tempo - em um processo que, com Contreras (2005), podemos associar a um uso ideológico da diversidade -, a valorização de produtos locais, tradicionais, artesanais.

A partir desse mesmo quadro, propomos refletir sobre as interfaces entre cultura alimentar e segurança alimentar e nutricional, sugerindo que desse modo possamos encontrar caminhos para apreender como se conformam, em uma sociedade, adesões, adaptações ou rejeições a práticas alimentares nela introduzidas. 


\section{O CASO DA BATATA-DOCE DE POLPA ALARANJADA EM MOÇAMBIQUE}

A batata-doce de polpa alaranjada foi introduzida em Moçambique no final dos anos 1990, por meio de parceria entre o Instituto Nacional de Investigação Agronômica (INIA), de Moçambique, e o International Institute of Tropical Agriculture (IITA), com sede na Nigéria, relação que proporcionou a realização de pesquisas para desenvolver variedades melhor adaptadas às condições de solo e clima moçambicanos.

No ano 2000, ocorreram enchentes, intensas como nunca se havia visto, que devastaram a região Sul do país, abrangendo as províncias de Maputo, Gaza e Inhambane. Na sequência das cheias, nessas regiões houve eclosão de doenças endêmicas, associadas à fome, consumo de água imprópria e de alimentos pouco nutritivos.

Diante da situação, o INIA propôs a introdução e estímulo da produção e consumo de batata-doce de polpa alaranjada. Seis meses após o início da distribuição de ramas do tubérculo, foi observada melhoria significativa no estado nutricional da população, principalmente entre crianças. Notou-se também decréscimo de mortes por desnutrição e de doenças endêmicas. Esses resultados - alcançados também porque concomitantemente houve ações nas áreas de higiene e moradia, entre outras - reforçaram a visão de que a insegurança alimentar e nutricional poderia ser controlada por meio da produção local, cabendo à batata-doce de polpa alaranjada um importante papel, especialmente na alimentação de crianças.

Esses fatos levaram à elaboração de programa nacional para erradicação da insegurança alimentar e nutricional. Assim, por meio de campanhas e serviço de extensão rural, o governo promoveu o cultivo e consumo em massa de batata-doce de polpa alaranjada, isso não apenas entre as famílias rurais afetadas no Sul do país, mas em iniciativa dirigida ao conjunto da população nacional: toda e qualquer pessoa que tivesse algum espaço disponível deveria cultivar o tubérculo.

Contudo, ainda que inicialmente o cultivo de batata-doce de polpa alaranjada em Moçambique tenha apresentado resultados positivos, após o término do programa, verificou-se, em boa medida, abandono em sua produção e consumo. Esse cenário conduz à pertinência de repensar estudos sobre monitoria e avaliação de programas que, tal como aquele que estimulou a produção e o consumo de batata doce de polpa alaranjada em Moçambique, comumente estabelecem seus parâmetros sem contemplar questões sociais, culturais ou étnicas associadas às trajetórias das famílias e aos padrões alimentares historicamente estabelecidos. Habitualmente, tais estudos se limitam a mensurar resultados a partir de critérios nutricionais ou de ganhos monetários referentes, respectivamente, ao consumo e cultivo de batata-doce de polpa alaranjada. Nesse quadro é que a pesquisa aqui apresentada foi concebida, buscando apreender, a partir dos saberes e práticas da alimentação das famílias rurais estudadas, classificações que orientam a valoração da comida e percepções sobre (in)segurança alimentar.

Durante o processo de colonização do país, diversos cultivos foram introduzidos em Moçambique, dentre eles a batata-doce (de polpa branca, inicialmente destinada à alimentação do gado), daí sua presença remeter à memória da opressão portuguesa, o que transparece em depoimentos de alguns dos interlocutores da pesquisa realizada. 
Entre os interlocutores que evidenciam a associação entre a batata-doce e os portugueses, é relevante a perspectiva do senhor Alterro, que, em sua narrativa, associa o surgimento desse cultivo em Moçambique ao tempo da dominação portuguesa, cuja fase mais dramática, a fase colonial propriamente dita, teve início por volta de $1918^{4}$, quando a administração portuguesa passou a interferir mais diretamente no modo de organização familiar, na cultura, hábitos e valores da população. Na mesma perspectiva, vale trazer um trecho do depoimento de outro interlocutor:

Não podíamos fazer nossas festas, éramos proibidos. Tínhamos que comer o que eles comiam e fazer o que eles queriam, para ser assimilado, caso contrário você era alvo de tortura e escravidão. Mas, mesmo assim, muitos preferiam morrer que se submeter (AVIRAMUMO).

A assimilação, termo empregado tanto por Alterro quanto por Aviramumo, não apenas pressupunha a rejeição à identidade de origem, cultura, hábitos e costumes tradicionais como também possibilitava distinção que permitia reconhecimento da condição de cidadania portuguesa. Tal situação, marcada pelo processo agressivo de penetração colonial portuguesa em Moçambique, teria fim, ao menos do ponto de vista político, apenas em 1975, após dez anos de luta armada, com a proclamação da independência nacional.

Esse histórico constitui o contexto que possibilita apreender a associação, em Moçambique, entre o cultivo de batata-doce e a desestruturação social decorrente da dominação e exploração colonial, processo marcado pela dissolução de tribos, clãs e famílias, decorrente do deslocamento forçado de homens e mulheres para o trabalho escravo em fazendas de propriedade de colonizadores e para o tráfico negreiro. Contudo, paradoxalmente, ainda que a batata-doce tenha sido associada à penetração indesejada e violenta de colonizadores em Moçambique, ela se constituía em alimento que, pelo menos do ponto de vista biológico, minimizava a escassez de víveres, também decorrente do processo de desestruturação social das comunidades nativas. É em tal quadro que o plantio de batata-doce caracterizou-se como atividade infantil: era o cultivo que as crianças, privadas do convívio com os familiares adultos, podiam realizar em torno da casa, buscando assegurar seu sustento. Foi desse modo que, na zona estudada, a batata-doce constituiu-se, nas palavras de Mirasse (2010), como alternativa negativa, ou seja, como opção que, longe de ser a desejável no que se refere aos hábitos alimentares anteriores à colonização e à manutenção dos laços sociais, era o alimento possível, em um contexto de crescente vulnerabilidade social e alimentar.

Após a independência, com o passar dos anos, o tecido social se recompôs e antigos costumes foram recuperados. As famílias rurais voltaram a cultivar mandioca, arroz, milho, mapira e mexoeira ${ }^{5}$. A presença da batata-doce de polpa brancas e manteve, mas sua produção é realizada sob a responsabilidade de crianças, sendo seu consumo dirigido a elas. Desse modo, não sendo produzida nas áreas de cultivo principais, por adultos, e não sendo destinada à comercialização, o cultivo da batata-doce não é considerado trabalho e, por isso, não traz honra para a família.

Por não ser considerada comida — recordemos a distinção entre alimento e comida, proposta por DaMatta (1987), que entende que um alimento apenas será comida quando expressão da cultura do grupo, remetendo a sua identidade e cultura alimentar - , a batata-doce não deve ser oferecida a convidados e, também por isso, seu consumo é circunscrito a momentos de não-trabalho. Tal associação entre o consumo da batata-doce com não-trabalho se deve ao fato de que, como explicaram os interlocutores da pesquisa, a batata-doce — não apenas a de polpa alaranjada, também a branca — provoca azar, ou 
mahussi, na língua local. Segundo explicações fornecidas pelos interlocutores da pesquisa, esse azar consiste em sofrimento decorrente de causa inexistente, ou seja, ter azar significa sofrer sem motivo. Desse modo, ainda que não se tenha feito qualquer coisa errada, se a pessoa tem azar, não se acredita nela, sendo sentenciada e, após execução da sentença, sendo revelados os fatos, percebe-se que a puniram sem necessidade: as pessoas dirão que foi azar. É nesse quadro que podemos entender o trecho de depoimento reproduzido a seguir, de um interlocutor da pesquisa indagado sobre como entende o mahussi.

Foi daí que ele concordou, porque eu sempre digo para ele, meu filho, nos dias em que você vai para escola, não coma batata-doce, é melhor, se não tiver outra coisa para comer ou levar como lanche, prefira passar a fome até onde você puder aguentar (LIVURA).

Considera-se que a batata-doce dá azar quando produzida e quando consumida. É assim que a realização de sua produção em consorciamento com outros cultivos, bem como a preferência por destiná-la à comercialização - ao invés de direcioná-la ao autoconsumo -, constituem-se em astúcias, como diria Certeau (1998), estratégias que buscam minimizar o azar.

Ainda, dada a associação da batata-doce à opressão vivida pelos moçambicanos à época da colonização portuguesa, acredita-se que, ao comer o tubérculo ou ao dedicar tempo a seu cultivo, incorre-se em desrespeito aos sacrifícios feitos pelos antepassados quando submetidos à situação de escravidão e à honra associada a sua resistência e luta diante da opressão. Dessa deslealdade em relação aos antepassados adviria o azar, reivindicado pelos espíritos dos ancestrais que se sacrificaram pela soberania do povo.

\footnotetext{
Não ligo para a produção da batata-doce, não diz nada para mim [...] Eu deixo para minha mulher e os filhos fazerem [...] Eu cuido de coisas sérias e não de brincadeiras. Luto sempre para ter maior quantidade de mandioca e milho, isso sim vai garantir que a gente não passe fome e eu não fique envergonhado (ALFINETE).
}

Como indica Alfinete no trecho de depoimento reproduzido acima, ao tempo que a batata-doce não é proibida, é classificada como alimento de menor importância. Em sua fala, enquanto o interlocutor hierarquiza alimentos, classificando mandioca e milho como superiores em relação à batata-doce, também indica uma hierarquia familiar, sugerindo - tal como observado em alguns dos estudos clássicos sobre o campesinato brasileiro (HEREDIA, 1979; WOORTMANN E WOORTMANN, 1997), que evidenciam a distinção entre o roçado e o roçadinho, sendo que no primeiro, sob responsabilidade dos homens, são realizados os cultivos comerciais e os que asseguram o suprimento alimentar da família; enquanto no segundo, cultivado por mulheres, jovens e crianças, encontra-se uma produção considerada complementar, "miudezas" - que o trabalho dos homens é mais importante que o trabalho de mulheres e crianças. Comentando a desvalorização da produção de batata-doce, em seu depoimento, o senhor Camido deixa transparecer que, não fosse pelo estímulo governamental, não cultivaria batata-doce. Segundo seu relato, apenas na infância a havia produzido, depois que se tornou jovem, jamais voltara a cultivar e raramente comia o tubérculo.

Eu faço parte da associação que produz rama para vender e também produzimos a batata-doce de polpa cor alaranjada, que vendemos para organizações não governamentais e pessoas de fora, mas eu nunca trago aqui em casa (CAMIDO). 
Além de não plantar e não consumir batata-doce - o que é reafirmado por dona Iria, esposa de Camido, que conta que o marido jamais come batata-doce, seja branca, amarela ou de outra cor -, o interlocutor narra que, agora que tem sua família, transmitiu a seus filhos os ensinamentos que prescrevem restrições em relação ao tubérculo.

Contudo, curiosamente, quando há distribuição de ramas por parte de técnicos da agricultura ou de organização não governamental, ao invés de uma criança, é o pai ou a mãe da família que a eles se dirige para recebê-las, pois de outro modo poderia ser interpretado como falta de respeito perante as autoridades, podendo resultarem a família ficar marcada e não voltar a receber auxílios em programas futuros. Esse é o quadro em que, apesar do incentivo à produção de batata-doce de polpa alaranjada, seu consumo diminui. Mesmo levando em consideração o que é plantado nas áreas de cultivo manejadas pelas crianças, o volume produzido do tubérculo não justifica os investimentos carreados ao programa.

No entanto, como visto, enquanto a produção e o consumo de batata-doce são rejeitados, a mandioca - cujo cultivo foi introduzido em Moçambique antes do da batata-doce - é considerada uma bênção. Diferentemente do que ocorre em relação à batata-doce, em Nampula é o chefe da família quem tem o direito de cuidar desse cultivo, atividade que proporciona honra. Toda atividade relacionada à mandioca é classificada como trabalho. Os diferentes pratos elaborados a partir da mandioca são considerados comida e, portanto, recomenda-se seu consumo para assegurar força, prazer e saciedade. Além disso, o consumo de mandioca não apresenta restrições culturais. Os convidados deverão ser servidos com mandioca quando se quer desejar-lhes boas-vindas e tratar-lhes com respeito, porque seu consumo fortalece. A mandioca é, assim, base dos pratos servidos nas festas tradicionais.

Em síntese, ainda que a batata-doce de polpa alaranjada seja nutricionalmente significativa, seu emprego para combater a insegurança alimentar pode, no contexto estudado, ser considerado pouco eficaz, uma vez que, além de não considerado como comida, é produto associado a azar e cujo cultivo é restrito às crianças, não havendo, desse modo, interesse em incrementar sua produção.

\section{À GUISA DE CONCLUSÃO: CULTURA ALIMENTAR E SEGURANÇA ALIMENTAR E NUTRICIONAL}

Para melhor apreender as implicações do programa voltado à difusão de batata-doce de polpa alaranjada em Moçambique enquanto estratégia para promoção de segurança alimentar e nutricional, é válido considerar, como propõe Garine (1987), a descontinuidade entre os campos biológico e cultural no que se refere às escolhas alimentares. $\mathrm{O}$ autor toma como exemplo as sociedades industrializadas, com estilos de vida marcados por crescente sedentarismo, o que supostamente deveria conduzir à redução do aporte energético. No entanto, ao contrário, o que se observa é que essas sociedades têm adotado dietas ricas em proteínas animais, açúcares, gorduras e produtos estimulantes e intoxicantes.

Essa descontinuidade entre os campos biológico e cultural pode ser entendida como evidência de que as sociedades humanas fazem seleção das possibilidades alimentares disponíveis, mas que não necessariamente as escolhas são realizadas apenas - ou sequer principalmente - em virtude de aspectos 
biológicos, dado que, muitas vezes, potencialidades alimentares são negligenciadas. Ainda segundo o autor citado,

O homem se alimenta de acordo com a sociedade a que pertence. Sua cultura define as opções sobre o que é comestível e as proibições alimentares que eventualmente o distinguem de outros grupos humanos (GARINE, 1987, p. 4).

Assumindo, portanto, que as escolhas alimentares de cada sociedade não são realizadas levando-se em consideração apenas ou principalmente as potencialidades nutricionais dos alimentos disponíveis, cabe refletir sobre segurança alimentar e nutricional enfatizando os aspectos culturais associados à alimentação. Nesse sentido, o caso apresentado neste artigo, da batata-doce de polpa alaranjada no contexto moçambicano, configura-se como particularmente emblemático. Mesmo em situação de insegurança alimentar, o tubérculo encontrou resistência, pois, ainda que no campo biológico/nutricional pudesse representar potencial alimentar significativo, sob a perspectiva cultural, dado o modo como, no período colonial, esteve associado à opressão infringida ao povo moçambicano, sua difusão pouco provavelmente encontraria acolhida.

Também Maluf (2007), ao discutir segurança alimentar e nutricional nos contextos brasileiro e internacional, reconhece a pertinência de compreender a "natureza dinâmica das culturas alimentares e dos aspectos positivos do intercâmbio entre elas" (MALUF, 2007, p. 142), ressaltando a necessidade de contemplar a perspectiva da soberania alimentar, de criar instrumentos de regulação dos mercados alimentares e de proteger práticas e saberes constitutivos da cultura alimentar. Para esse autor, também nessa discussão é evidenciada a elevada desigualdade social do Brasil, já que

pelo lado da produção e distribuição dos alimentos, a dimensão cultural também está contida na perspectiva de promover os pequenos e médios empreendimentos urbanos e rurais, agentes potencialmente portadores de diversidade, em face da hegemonia da grande produção e distribuição. Pelo lado do consumo, ela implica atuar sobre a incorporação de novos hábitos alimentares pelos diferentes segmentos da população, em alguns casos por razões de custo dos produtos, e de uma maneira geral por influência da publicidade (MALUF, 2007, p. 143).

Esses argumentos estimulam trazer a análise realizada sobre o caso estudado para iluminar o contexto brasileiro ou outro que assumamos complexo e diverso. De fato, se tomarmos o caso das restrições subjacentes à produção e consumo de batata-doce - e em particular de batata-doce de polpa alaranjada - em Moçambique, pode-se argumentar que, em conformidade coma própria definição de Segurança Alimentar e Nutricional, apresentada no início deste artigo, dada a diversidade de biomas, regiões e hábitos alimentares, para políticas efetivas voltadas à construção da segurança alimentar e nutricional, é preciso apreender em profundidade as relações dos diversos grupos sociais com biomas e regiões, buscando identificar o que é considerado comida em cada lugar. Como indaga Garine (1987), o que é comida ou do que se alimenta cada sociedade? Tal debate segue atual e pertinente e, ainda que, como discutido na parte inicial do artigo, global e local, moderno e tradicional coexistam, é preciso que hábitos alimentares diversos sejam reconhecidos e valorizados.

Isso posto, investimentos na identificação e legitimação de produtos e hábitos alimentares locais são não apenas necessários, mas imprescindíveis, sob pena de, em nome de preceitos de uma suposta (e hegemônica) alimentação saudável, serem comprometidos não apenas práticas e conhecimentos mobilizados na produção de alimentos singulares de cada região como também elos 
fundamentais para a construção da segurança alimentar e nutricional de grupos sociais diversos que, para além da comida em si, remete à sociabilidade na qual a alimentação e os hábitos alimentares estão imersos.

\section{NOTAS}

${ }^{1}$ A Lei n ${ }^{\circ} 11.346$, de setembro de 2006, criou o Sistema Nacional de Segurança Alimentar e Nutricional - SISAN.

${ }^{2}$ Essa pesquisa foi desenvolvida enquanto dissertação de mestrado de Jone Mirasse, um dos autores deste artigo, realizada junto ao Programa de Pós-Graduação em Desenvolvimento Rural da Universidade Federal do Rio Grande do Sul (PGDR/UFRGS) e no âmbito do Grupo de Estudos e Pesquisas em Alimentação, Consumo e Cultura GEPAC (ver: http://www.ufrgs.br/pgdr/gepac). O trabalho está disponível em: https:// lume.ufrgs.br/bitstream/handle/10183/30850/000774885.pdf?sequence=1\&isAllowe$\mathrm{d}=\mathrm{y}$.

${ }^{3}$ Para um breve panorama da trajetória dos estudos em alimentação e cultura, ver Menasche et al. (2012).

${ }^{4}$ Até essa época, os povos, organizados em impérios, travaram, por cerca de duas décadas, lutas de resistência à dominação colonial portuguesa.

${ }^{5}$ A mapira (Sorghum bicolor L.) e a mexoeira (Pennisetumglaucum) são cereais que costumam ser consumidos apenas como xima (polenta), após secagem ao sol e debulha e moagem dos grãos.

\section{REFERÊNCIAS}

BRASIL. Lei $n^{\circ} 11.346$, de 15 de setembro de 2006. Cria o Sistema Nacional de Segurança Alimentar e Nutricional (SISAN) com vistas em assegurar o direito humano à alimentação adequada e dá outras providências. Presidência da República, Casa Civil, 2006. Disponível em: http://www.planalto.gov.br/ ccivil_03/_Ato2004-2006/2006/Lei/L11346.htm. Acesso em: 26 jun. 2012.

CANCLINI, Nestor G. Consumidores e cidadãos. Rio de Janeiro: Ed. UFRJ, 1997.

CERTEAU, Michel de. A invenção do cotidiano: artes de fazer. Petrópolis: Vozes, 1998.

CONTRERAS, Jesús. Patrimônio e globalização: o caso das culturas alimentares. In: CANESQUI, Ana Maria; GARCIA, Rosa Wanda (orgs.). Antropologia e Nutrição. Um diálogo possivel. Rio de Janeiro: Fiocruz, 2005.

DAMATTA, Roberto. Sobre o simbolismo da comida no Brasil. O Correio da UNESCO, v. 15, n. 7, p. 22-23, 1987.

FLANDRIN, Jean Louis; MONTANARI, Massimo. Hoje e amanhã. In: (orgs.). História da Alimentação. São Paulo: Estação Liberdade, 1998.

FREITAS, Maria do Carmo S. Uma abordagem fenomenológica da fome. Revista de Nutrição, v. 15, n. 1, p. 53-69, 2002.

FREITAS, Maria do Carmo S. Agonia da fome. Salvador: Ed. UFBA, 2003.

GARINE, Igor de. Alimentação, culturas e sociedades. O Correio da UNESCO, v. 15, n. 7, p. 4-7, 1987.

GARRIGUES-CRESSWELL, Martine; MARTIN, Marie Alexandrine. L'alimentation: entre mondialisation et expression identitaire. Techiques\&Culture, n. 31-32, p. 1-16, 1998.

HEREDIA, Beatriz Maria Alásia de. A morada da vida: trabalho familiar de pequenos produtores do Nordeste do Brasil. Rio de Janeiro: Paz e Terra, 1979. 
MALUF, Renato S. J. Segurança Alimentar e Nutricional. Conceitos fundamentais. Petrópolis: Vozes, 2007.

MENASCHE, Renata; ALVAREZ, Marcelo; COLLAÇO, Janine H. L. Alimentação e cultura em suas múltiplas dimensões. In: (orgs.). Dimensões socioculturais da alimentação. Diálogos latino-americanos. Porto Alegre: Ed. UFRGS, 2012.

MINTZ, Sidney W. Comida e antropologia: uma breve revisão. Revista Brasileira de Ciências Sociais, v. 16, n. 47, p. 31-41, 2001.

MIRASSE, Jone Januário. O consumo de batata-doce de polpa alaranjada entre famílias rurais do nordeste de Moçambique: um estudo sobre percepções de comida e Segurança Alimentar na província de Nampula. Dissertação (Mestrado em Desenvolvimento Rural), Universidade Federal do Rio Grande do Sul, Porto Alegre, 2010.

RIAL, Carmen S. M. Fast-foods: a nostalgia de uma estrutura perdida. Horizontes Antropológicós, v. 2, n. 4, p. 94-103, 1996.

ROCHA, Everardo P. G. Magia e capitalismo. Um estudo antropológico da publicidade. São Paulo: Brasiliense, 1985.

WOORTMANN, Ellen F.; WOORTMANN, Klaas. O trabalho da terra: a lógica e a simbólica da lavoura camponesa. Brasília: Ed. UnB, 1997. 